\title{
Pediatric emergency room activities in Italy: a national survey
}

\author{
Riccardo Longhi ${ }^{1 *}$, Raffaella Picchi ${ }^{1}$, Domenico Minasi ${ }^{2}$ and Alessandra Di Cesare Merlone ${ }^{1}$
}

\begin{abstract}
Background: In Italy, the number of accesses to the Emergency Units has been growing for the past 30 years. This, together with a low coordination between hospital and peripheral pediatric services, has brought to an unnecessarily high number of hospital admissions. For this reason, it is essential to plan and implement strategies able to improve the appropriateness of hospital admissions. In the '90s, the Short Stay Observation was extended to pediatric patients. As highlighted by the report "Guidelines for Pediatric Observation Units" (2005), patients receive considerable benefits from a short hospital permanence. The purpose of the study is to report data about the Pediatric Emergency Room activities in Italy.

Methods: In 2011, the Italian Society of Pediatrics promoted an online data collection to investigate organization and activity of Italian Pediatric and Neonatal Units. A form, containing 140 questions, was sent to 624 Pediatric and Neonatology Units. This study will be focused only on data regarding pediatric Emergency Rooms (E.R.) and Observation Units.

Results: 237 units replied, 183 if we focus on units with pediatric inpatient service. Based on the results, E.R Units were provided with a dedicated pediatrician in $56 \%$ of the cases: of these, $85 \%$ for $24 \mathrm{~h}$. The majority of the patients were seen by a pediatrician. In only $8 \%$ of the units, patients visited by a pediatrician were less than $40 \%$. The age limit was 14 years in $60 \%$ of the cases. In $72 \%$ of participating units a E.R. triage was carried out. Only $18 \%$ of units registered more than 10000 E.R. visits/year. The percentage of children hospitalized after accessing the E.R. was significantly higher in southern regions (more than $20 \%$ of the units hospitalized more than $40 \%$ of children entering the E.R.). $66 \%$ of the units were provided with an Observation Unit. In $61 \%$ of the cases, the duration did not exceed $24 \mathrm{~h}$. In more than half of the structures, less than $10 \%$ of the E.R. visits went into observation. The type of remuneration was not homogeneous.
\end{abstract}

Conclusions: The study highlights the heterogeneity of the Italian reality, with great possibilities for improvement, especially in southern regions.

Keywords: Short stay observation, S.S.O, Emergency units

\section{Background}

In Italy, the number of Emergency Room (E.R.) admissions of adult and pediatric patients has been growing considerably over the past 30 years. In 2005, the Ministry of Health Advisory Committee launched the "Emergency System Improvement Plan". At that time, nearly 50 million visits per year were registered. Pediatric patients represented the $10-15 \%$ of the overall number [1].

\footnotetext{
*Correspondence: riccardo.longhi0310@gmail.com

'Unità Operativa di Pediatria, Ospedale Sant'Anna, San Fermo della Battaglia, Como, Italy

Full list of author information is available at the end of the article
}

Ninety percent of the cases were admissions, without there having been any previous contact with a medical practitioner. This being due to the fact that the highest concentration of admissions was registered during holidays and weekends. Moreover, data showed that most patients admitted to E.R. were coded either white or green (low degree of severity as opposed to yellow or red, high or very high severity).

Based on this information, it seems clear that the lack of interaction and cooperation between hospitals and family practitioners represents one of the main causes for the high E.R. admissions registered in the Country. 
There is, therefore, an urgent need to plan and implement new strategies i order to best utilize E.R. facilities.

In Italy, Short Stay Observation (S.S.O.) was extended to pediatric patients for the first time in 2003, for the purpose of continued care and treatment for patients in E.R., as well as reducing discomfort for both children and families, as highlighted by the report "Guidelines for Pediatric Observation Units" (2005) [2].

The aim of this study is to analyze the Italian Pediatric Emergency Room activities focusing our attention primarly on the S.S.O. service. This approach has the potential to become an extremely useful tool in decreasing and optimizing pediatric hospital admissions. To achieve this goal, we used the results of a national survey launched in 2011 and edited by the Italian Society of Pediatrics. The survey focused on the activity of Pediatric and Neonatal Departments in Italy, in 2010.

\section{Methods}

In 2007, the Italian Society of Pediatrics promoted an online, multiple choice, data collection in order to investigate the organizational structure and activities of Pediatric and Neonatal Units. A specific form to collect informations was used.

Four years later, in 2011, the research process was repeated, this time focusing on the activity in 2010. Data collection took place from May until December 2011. The present study is based on the results of this last survey.

The form consisted of 140 questions concerning various hospital activities: from ordinary admissions to Day Hospital, Day-Surgery, E.R., S.S.O., Nursery, Neonatal Pathology, Neonatal Intensive Care Unit and Outpatient Clinics. This study will focus only on pediatric E.R. and S.S.O. activities.

Italy was divided into 3 macro areas: northern Italy (Emilia Romagna, Friuli Venezia Giulia, Liguria, Lombardy, Piemonte, Trentino Alto Adige, Valle d'Aosta and Veneto); central Italy (Abruzzo, Lazio, Marche, Tuscany and Umbria); southern Italy (Basilicata, Calabria, Campania, Molise, Puglia, Sardinia and Sicily).

The questionaire (Table 1) was sent to 624 Pediatric and Neonatology Units around the Country. 237 replied: 117 in northern Italy (49\%), 48 in central Italy (20\%), and 72 in southern Italy (31 \%).

Statistical analysis was performed using the chi-square test considering significant a $p$ value $<0,05$.

Some data were processed utilizing linear regression test, in order to analyze a possible functional relationship between considered variables (in our study, the percentage of admissions from E.R. and the number of E.R. admissions).

\section{Results and discussion Response rate}

Overall, when compared with the survey conducted in 2007 [3], there was a significant decrease in the percentage of responses, that dropped from 80 to $39 \%$ $(p<0,001)$.

The survey showed the prevalence of Public Hospitals both in the group of the contacted facilities and in the group that actually participated in the survey: 84 and $83 \%$, respectively. University Hospitals represented respectively 8 and $11 \%$; Pediatric Hospitals 5 and $2 \%$ and accredited Private Hospitals 2 and $4 \%$. Uncredited Private Hospitals represented $1 \%$ of contacted units but their participation in the survey was null.

\section{Pediatrician coverage of ward and E.R}

Almost $83 \%$ of the units ensured a 24-h medical coverage (196), while $17 \%$ (41) offered a 12-h coverage. In $75 \%$ of the cases, (177) there was an operating on-call availability service. Table 2 illustrates the geographical distribution of these parameters with significant differences between northern and southern regions as reported (coverage h24 $p$ 0.024; coverage h12 $p$ 0.024; on-call availability service $p$ 0.009).

Focusing on units with pediatric inpatient service (associated or not to neonatal activities), the number decreased from 237 to 183 (Fig. 1). 57 \% (104) managed pediatric patients in adult E.R., $27 \%$ (49) in pediatric E.R. and $16 \%$ (30) in General Emergency Departments (DEA), with an uneven geographical distribution, as reported in Fig. 2.

There was a pediatrician assigned to the E.R. in $56 \%$ of the units: in $85 \%$ (89) of them for $24 \mathrm{~h}$ and in $15 \%$ (14) only for $12 \mathrm{~h}$ during the day time.

In $45 \%$ of the cases (82) access to the pediatrician was direct, in $37 \%$ (67) only by the request of the general E.R. physician and in $18 \%$ (34) it was direct, with the exception of a few previously agreed upon pathologies. Table 2 illustrates the geographical distribution of these parameters. In particular, it seems that in the E.R. of northern hospitals, the number of children seen directly by a pediatrician is significantly higher than in the rest of the Country $(p<0,001)$.

Altogether, the percentage of patients seen by a pediatrician varied. In more than $66 \%$ of the cases the pediatrician saw approximately $80 \%$ of the children entering the E.R. Conversely, in $8 \%$ of the cases, the percentage of children seen by the pediatrician was less than $40 \%$. The age limit was 14 years in $60 \%$ of the cases, 17 in $26 \%, 16$ in $11 \%$ and 15 in $3 \%$ of the cases, with significant differences between north and south regarding age limit for admission of 14 years old $(p<0.001)$ and of 17 years old $(p<0.001)$ and between center and south $(p 0.007$ and $p 0.004$ respectively) as reported in Table 2 . 
Table 1 Extract of the questionnarie with the questions pertinent to this study

\begin{tabular}{|c|}
\hline ER ACTIVITY \\
\hline ER PEDIATRIC COVERAGE \\
\hline$\square 12$ HOUR $\square 24$ HOUR $\quad \square$ NONE \\
\hline PEDIATRIC ON-CALL AVAILABILITY \\
\hline$\neg$ YES $\square$ NO \\
\hline ER TYPE \\
\hline$\square$ ADULT ER $\quad \square$ PEDIATRIC ER $\quad \square$ GENERAL EMERGENCY DEPARTMENT \\
\hline PEDIATRICIAN DEDICATED TO ER \\
\hline$\square 12$ HOUR COVERAGE $\square 24$ HOUR COVERAGE $\square$ NONE \\
\hline ACCESS TO THE PEDIATRICIAN \\
\hline$\square$ DIRECT \\
\hline$\triangleright$ ONLY ON-REQUEST BY THE PHYSICIAN OF GENERAL ER \\
\hline$\square$ DIRECT, EXCEPT A FEW PREVIOUSLY AGREED UPON PATHOLOGIES \\
\hline PERCENTAGE OF ER PATIENTS VISITED BY PEDIATRICIAN \\
\hline PERCENTAGE OF PEDIATRIC PATIENTS IN TOTAL ER POPULATION \\
\hline AGE LIMIT FOR ER ACCESS \\
\hline$\square 14$ YEARS $\square 15$ YEARS $\square 16$ YEARS $\square 17$ YEARS \\
\hline PRESENCE OF TRIAGE \\
\hline$\square \mathrm{YES} \square \mathrm{NO}$ \\
\hline NUMBER OF ER VISITS PER YEAR: \\
\hline PERCENTAGE OF HOSPITALIZATION FROM ER \\
\hline O.B.I. ORGANIZATION AND ACTIVITY \\
\hline PRESENCE OF OBI \\
\hline$\neg \mathrm{YES} \square \mathrm{NO}$ \\
\hline TOTAL DURATION OF OBSERVATION \\
\hline$\square$ UP TO 24 HOUR $\square$ UP TO 48 HOUR \\
\hline NUMBER OF BEDS FOR OBSERVATION \\
\hline NUMBER OF OBSERVATIONS PER YEAR \\
\hline PERCENTAGE OF OBI FROM ER \\
\hline PERCENTAGE OF HOSPITALIZATIONS FROM OBI \\
\hline
\end{tabular}


Table 2 Distribution of the parameters for macro area, Italy and $p$ value

\begin{tabular}{|c|c|c|c|c|c|c|}
\hline & Parameters & North & Center & South & Italy & $P$ value $^{*}$ \\
\hline 1 & Coverage h24 & $90 \%(105 / 117)$ & $79 \%(38 / 48)$ & $77 \%(56 / 72)$ & $84 \%(196 / 237)$ & $0,0245 c$ \\
\hline 2 & Coverage h12 & $10 \%(12 / 117)$ & $21 \%(10 / 48)$ & $23 \%(16 / 72)$ & $16 \%(41 / 237)$ & $0,0245 c$ \\
\hline 3 & On call availability service & $68 \%(79 / 117)$ & $77 \%(37 / 48)$ & $85 \%(61 / 72)$ & $75 \%(177 / 237)$ & $0,0088 \mathrm{C}$ \\
\hline 4 & Pediatrician dedicated to E.R. h24 & $56 \%(51 / 93)$ & $47 \%(17 / 36)$ & $39 \%(21 / 54)$ & $48 \%(89 / 183)$ & \\
\hline 5 & Pediatrican dedicated to E.R. h12 & $12 \%(11 / 93)$ & $3 \%(1 / 36)$ & $4 \%(2 / 54)$ & $8 \%(14 / 183)$ & \\
\hline 6 & No pediatrician dedicated to E.R. & $33 \%(31 / 93)$ & $50 \%(18 / 36)$ & $57 \%(31 / 54)$ & $44 \%(80 / 183)$ & $0,0044 \mathrm{c}$ \\
\hline 7 & Direct access of all children to E.R. pediatrician & $47 \%(44 / 93)$ & $39 \%(14 / 36)$ & $44 \%(24 / 54)$ & $45 \%(82 / 183)$ & \\
\hline \multirow[t]{2}{*}{8} & Direct access to E.R. pediatrician except agreed diseases & $30 \%(28 / 93)$ & $8 \%(3 / 36)$ & $6 \%(3 / 54)$ & $18 \%(34 / 183)$ & 0,010a \\
\hline & & & & & & $0,00044 c$ \\
\hline \multirow[t]{2}{*}{9} & Access to pediatrician only on request from E.R. physician & $23 \%(21 / 93)$ & $53 \%(19 / 36)$ & $50 \%(27 / 54)$ & $37 \%(67 / 183)$ & $0,0010 a$ \\
\hline & & & & & & $0,0010 \mathrm{c}$ \\
\hline \multirow[t]{2}{*}{10} & E.R. triage & $86 \%(80 / 93)$ & $83 \%(30 / 36)$ & $39 \%(21 / 54)$ & $72 \%(131 / 183)$ & $0,0010 b$ \\
\hline & & & & & & $0,0010 \mathrm{c}$ \\
\hline \multirow[t]{2}{*}{11} & Age limit for admission 14 years & $52 \%(48 / 93)$ & $53 \%(19 / 36)$ & $80 \%(43 / 54)$ & $60 \%(110 / 183)$ & $0,007 b$ \\
\hline & & & & & & $0,0010 c$ \\
\hline $11 b$ & Age limit for admission 15 years & $4 \%(4 / 93)$ & $0 \%(0 / 36)$ & $4 \%(2 / 54)$ & $3 \%(6 / 183)$ & \\
\hline 12 & Age limit for admission 16 years & $9 \%(8 / 93)$ & $17 \%(6 / 36)$ & $9 \%(5 / 54)$ & $10 \%(19 / 183)$ & \\
\hline \multirow[t]{2}{*}{13} & Age limit for admission 17 years & $35 \%(33 / 93)$ & $30 \%(11 / 36)$ & $7 \%(4 / 54)$ & $26 \%(48 / 183)$ & $0,004 b$ \\
\hline & & & & & & $0,0010 c$ \\
\hline \multirow[t]{2}{*}{14} & Presence of S.S.O. & $80 \%(74 / 93)$ & $67 \%(24 / 36)$ & $43 \%(23 / 54)$ & $66 \%(121 / 183)$ & $0,025 b$ \\
\hline & & & & & & $0,0010 c$ \\
\hline 15 & S.S.O. fixed reimbursement & $57 \%(42 / 74)$ & $67 \%(16 / 24)$ & $40 \%(9 / 23)$ & $55 \%(67 / 121)$ & \\
\hline 16 & S.S.O. reimbursement linked to health services provided & $32 \%(24 / 74)$ & $21 \%(5 / 24)$ & $30 \%(7 / 23)$ & $32 \%(36 / 121)$ & \\
\hline 17 & S.S.O. reimbursement linked to disease type & $11 \%(8 / 74)$ & $12 \%(3 / 24)$ & $30 \%(7 / 23)$ & $15 \%(18 / 121)$ & $0,02 \mathrm{C}$ \\
\hline 18 & Length of S.S.O. less than $24 \mathrm{~h}$ & $55 \%(41 / 74)$ & $58 \%(14 / 24)$ & $83 \%(19 / 23)$ & $61 \%(74 / 121)$ & $0,019 c$ \\
\hline 19 & Length of S.S.O. less than $48 \mathrm{~h}$ & $45 \%(33 / 74)$ & $42 \%(10 / 24)$ & $17 \%(4 / 23)$ & $39 \%(47 / 121)$ & $0.019 c$ \\
\hline
\end{tabular}

${ }^{*} P$ value for differences between north and center (a), center and south (b), north and south (c). Only significative $\mathrm{P}$ are recorded $(p<0,05)$

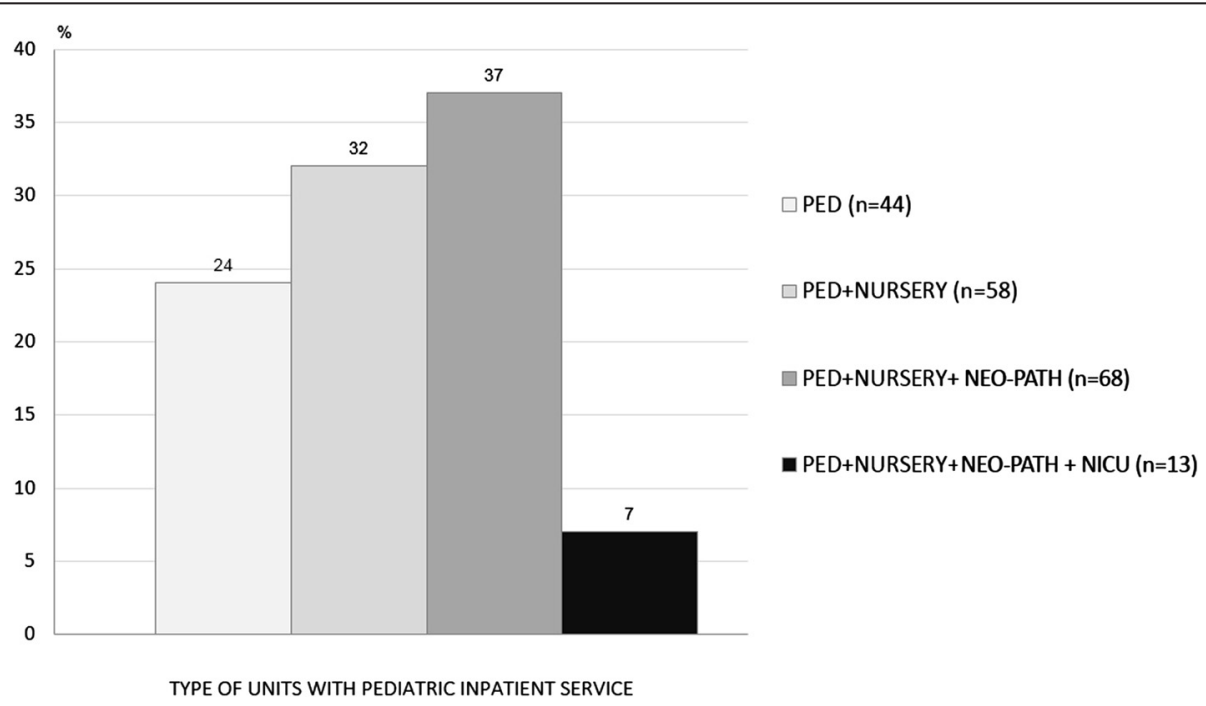

Fig. $1 \%$ distribution of facilities per type of units with pediatric inpatient service 


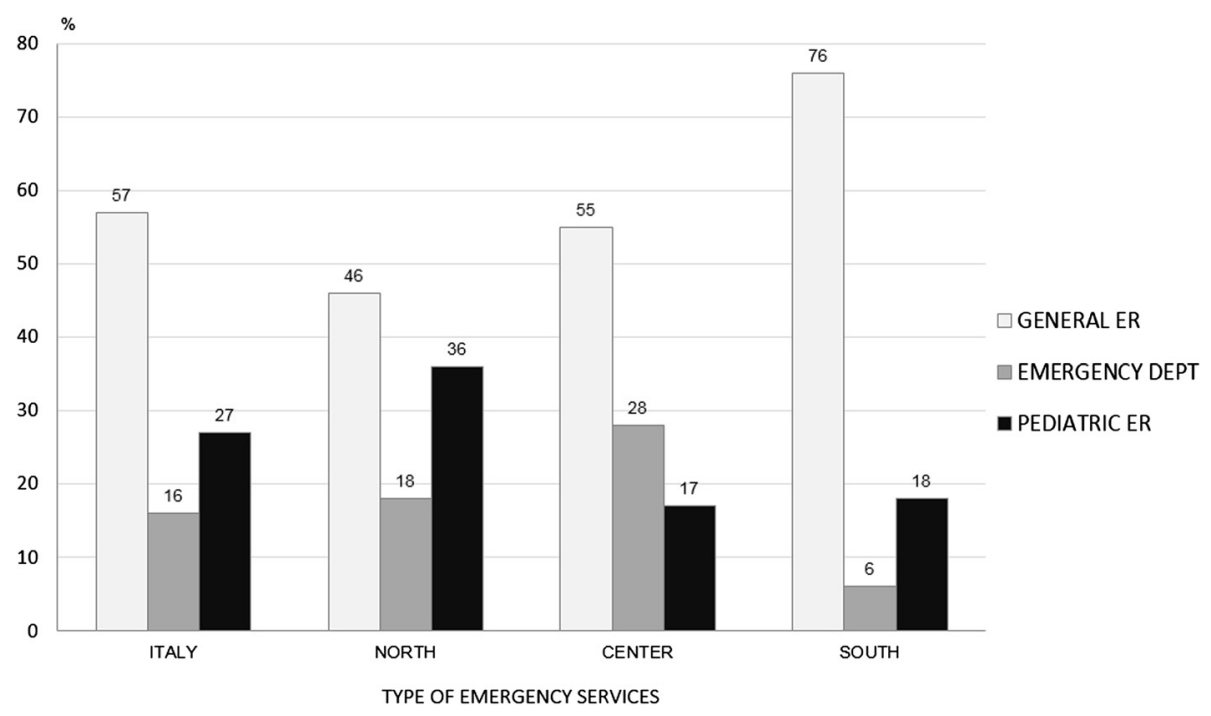

Fig. $2 \%$ distribution of facilities per type of emergency services: Italy and macro areas

\section{E.R. activity}

In $72 \%$ of the units (131), a triage was carried out, with a significant difference between northern and southern regions $(p<0.001)$ and between central and southern regions $(p<0.001)$ as reported in Table 2 . Only $18 \%$ of the facilities registered more than 10000 E.R. visits per year. The geographical distribution is shown in Fig. 3. Several units in the south registered a lower number of pediatric E.R. admissions (67\% of these facilities accepted less than 4000 pediatric patients per year). In terms of the actual percentage of children hospitalized after being admitted to the E.R., there was a huge difference between northern and southern Italy. In the north, $66 \%$ of the units hospitalized up to $10 \%$ of patients entering the E.R. vs $28 \%$ and $20 \%$ in the center and south, respectively ( $p<0,001$, north vs south; $p 0,01$, north vs center; $\mathrm{p}$ n.s. center vs south). Furthermore, in the south, more than $20 \%$ of the facilities hospitalized more than $40 \%$ of the children entering the E.R.

Figure 4 combines the values of E.R. admissions with those of hospitalization rate through E.R. with significant difference $(p<0,001)$ between north and center and north and south and no significant difference between center and south.

\section{S.S.O. organization and activity}

Sixty six percent (121) of the facilities were provided with an S.S.O. service. Again, the geographical distribution was not homogeneous: S.S.O. was available in $80 \%$ of the northern units, $67 \%$ of the central and only $43 \%$ of the southern units with significant differences between

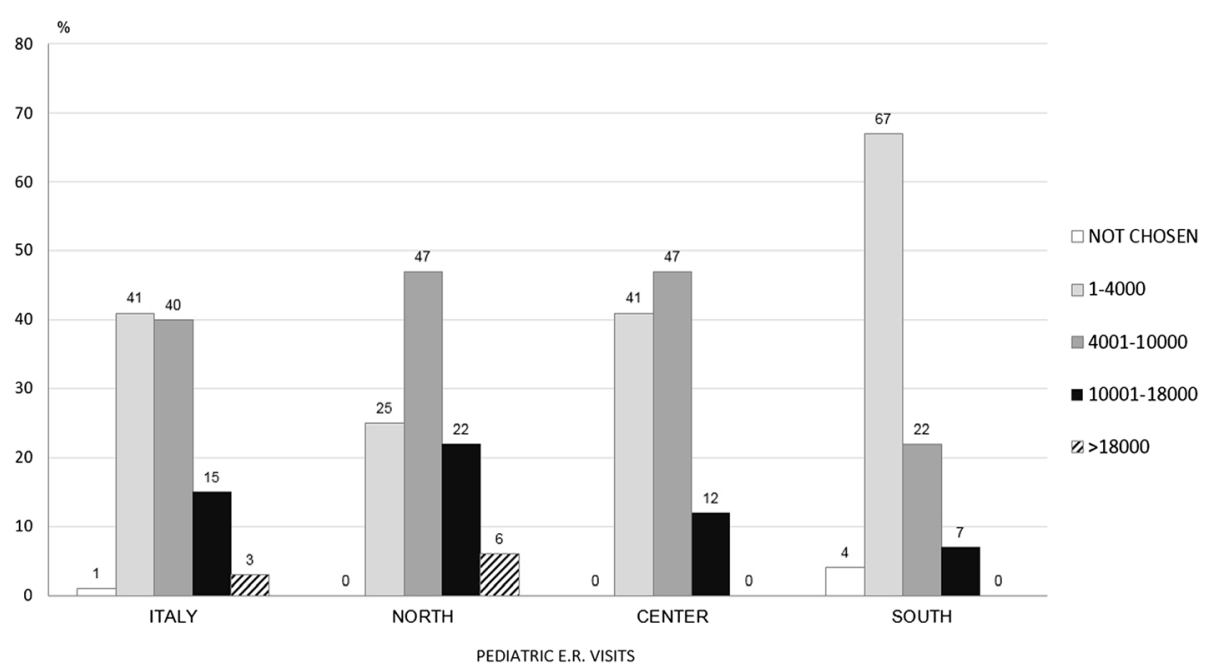

Fig. $3 \%$ distribution of facilities per pediatric E.R. visits: Italy and macro areas 

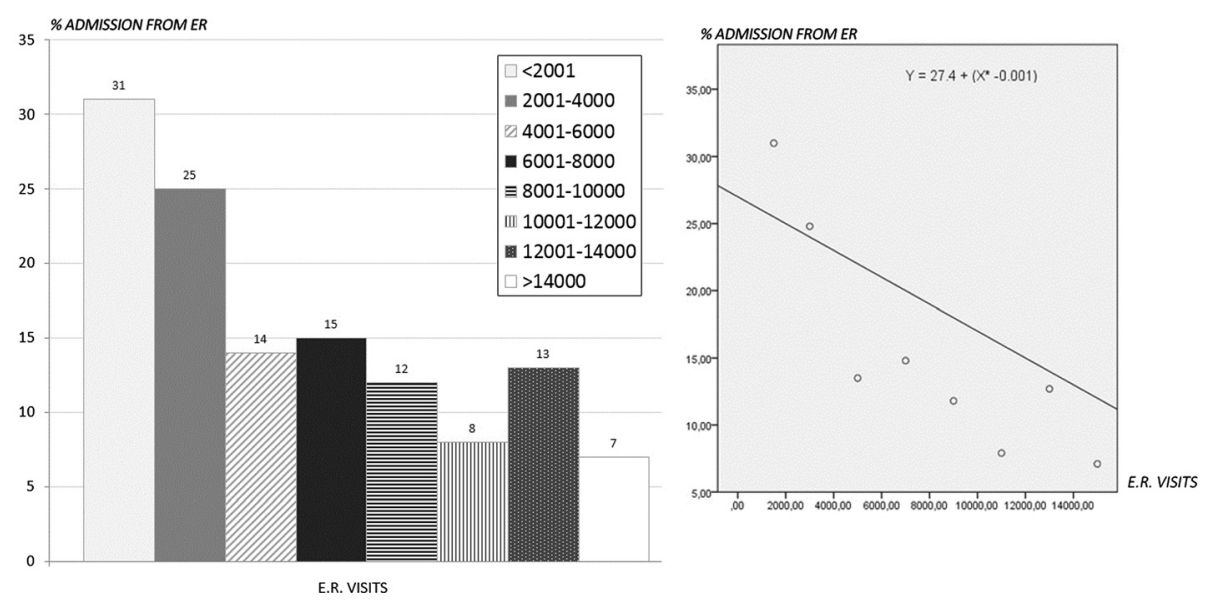

Fig. $4 \%$ distribution of admissions from E.R. per classes of numbers of E.R. visits (Italy) and regression line $(p<0,001)$

northern and southern regions $(p<0.001)$ and between center and southern regions $(p$ 0.025) as reported in Table 2.

In $61 \%$ of the facilities, the total duration of observation was limited to $24 \mathrm{~h}$. In the remaining $39 \%$, the duration could last for up to $48 \mathrm{~h}$. More specifically, in northern and central Italy, the number of observations with a length up to $24 \mathrm{~h}$ and those with a duration of up to $48 \mathrm{~h}$ were similar (55\% vs $58 \%$ and $45 \%$ vs $42 \%$ respectively). In the south, most facilities (83 \%) kept patients for up to $24 \mathrm{~h}$ (Table 2).

Seventy percent of the facilities were equipped with 1 or 2 beds, $24 \%$ had 3 or 4 beds and $6 \%$ were provided with more than 4 beds. The following statistics detail the volume of activity: approximately $12 \%$ performed less than 100 observations per year; $21 \% 100-250$; $30 \%$ 251-500; $21 \%$ 501-1000; $16 \%$ more than 1000.

\section{Discussion}

The data supplied by this research contribute to the task of evaluating the current state of Emergency services in Italy and in planning future strategies for improvement.

Unfortunately, there was a significant drop off in response rates to the questionaire from about $80 \%$ in 2007, to $39 \%$ in $2011(p<0,001)$.

There are potentially many reasons behind this reduction. Among these, a great deal of recent senior personnel turnover in pediatric units resulted in more barriers in communicating and coordinating with the new Directors. Another factor was that a large amount of activity data, rather difficult to obtain, mandatory in 2011, were omitted in the previous research. Lastly, the increasing work overload may have made it harder to make time to complete the questionaire.

Despite the low response rate seeming to compromise the representativeness of the data obtained, the characteristics of responding hospital facilities accurately reflect reality, with the only notable exception being Pediatric Hospitals, which responded to a lesser degree.

Results show that $83 \%$ of the units ensured an inpatient pediatric 24-h coverage, while $17 \%$ a $12-\mathrm{h}$ coverage with significant differences between northern and southern regions as represented in Table 2. In our opinion, these data are satisfactory, especially when compared with those of the previous survey (83\% vs $68 \%$ and $17 \%$ vs $18 \%$ respectively) (p n.s.). More specifically, the 24-h pediatric coverage has increased from 75 to $90 \%$ in the north (p n.s.); from 64 to $79 \%$ in the centre (p n.s.); and from 59 to $77 \%$ in the south (p n.s.). Furthermore, $56 \%$ of the units were equipped with a pediatrician dedicated to the E.R. in $85 \%$ of the cases for $24 \mathrm{~h}$ and in $15 \%$ of cases for $12 \mathrm{~h}$. In $48 \%$ of units, pediatricians examined more than $90 \%$ of children entering the E.R. Unfortunately, only in $27 \%$ of the facilities was there a Pediatric E.R.. In our opinion, this represents a warning regarding the idea of the" specificity of the pediatric area". This concept involves not only the proper and necessary separation of space from the adult population, but also the availability of a pediatric triage and nursing staff with specific expertise in pediatric care.

The data regarding the age limit pertaining to the pediatric area were absolutely unespected. In 2007, $40 \%$ of the participating units claimed to have hospitalized patients under 17 years. In 2011, this percentage dropped to $26 \%$ (p n.s.), while $60 \%$ of the units limited the admission to 14 years old patients. All three macro areas have lowered the age of pediatric competence, but to a different extent: $80 \%$ of southern facilities, for example, hospitalized patients only under 14 years, with a significant difference compared to northern facilities $(p<0.001)$ and centre facilities $(p 0.007)$ as shown in 
Table 2. The loss of competence toward the adolescents could be a serious concern for pediatricians and, more importantly, for that segment of the population.

Analysing the volume of E.R. activities, the data show that only $18 \%$ of the units made more than 10000 admissions per year. Most importantly, a considerable number of southern hospitals carried out less than 4000 E.R. visits a year. This information cannot be overstated, as it represents one of the most important causes of the high rate of admissions from E.R. (Fig. 4). None of the northern units hospitalized more than $40 \%$ of E.R. patients, while in the center and south, respectively $8 \%$ and $21 \%$ of the units hospitalized more than $40 \%$ of E.R. patients $(p<0,0001$, north vs south; $p 0,02$, north vs center and center vs south). Analogous results are obtained when we take into account the units that hospitalized between $25 \%$ and $40 \%$ of patients admitted to the E.R: $4 \%$ in the north, $27 \%$ in the centre and $36 \%$ in the south $(p<0,0001$, north vs south; $p 0,0001$, north vs centre; $p$ n.s. centre vs south). There are no rational reasons to explain these differences. The only explanation stems from the need to achieve a quota of admissions to justify the existence of those units that, otherwise, should be reallocated. Based on these results, it is clear that high rates of hospitalization correspond to low numbers of E.R. admissions. Figure 4 shows that facilities with less than 2001 E.R. admissions per year hospitalized more than $30 \%$ of patients vs $7,1 \%$ of those making more than 14000 E.R. admissions per year. The regression analysis shows a negative correlation between the number of E.R. visits and the percentage of admission from E.R.: smaller and lesser specialized facilities seem to have a higher hospitalization rate (Fig. 4).

These results highlight an urgent need to rationalize the prospect of emergency services. In our opinion, facilities with low E.R. admissions should be converted into outpatient clinics. This would lead to a decrease in the number of patients hospitalized, without compromising the quality and safety of care. In fact, the great majority of patients with serious medical problems would inevitably be directed to units providing 24-h pediatric coverage and equipped with an adequate number of pediatricians [4-7].

As pertaining to S.S.O., this assistance model was adopted by $66 \%$ of the participating units. Once again, the geographical distribution was not homogeneous. Almost $43 \%$ of the southern units offered S.S.O. services vs $67 \%$ of the central and $80 \%$ of the northern ones. Statistical analysis confirmed significant differences between northern and southern regions $(p<0.001)$ and between central and southern regions ( $p$ 0.025) (Table 2).

As for the S.S.O. time limit, it was less than $24 \mathrm{~h}$ in $61 \%$ of centers $(55 \%$ in northern regions, $58 \%$ in central and $83 \%$ in those southern), less than $48 \mathrm{~h}$ in $39 \%$ of centers (45\% in the north, $42 \%$ in the centre and $17 \%$ in the south). These data seem appropriate. In fact, in the United States, about one-third of pediatric patients hospitalized had a length of stay up to $48 \mathrm{~h}$, and therefore, it would have been manageable in S.S.O. [8-10]. These data become even more significant when, in addition to focusing on the length of stay, patients are classified by their diseases. For some diseases (asthma, croup), the percentage of hospitalizations "avoided" and "saved" reached $70 \%$ [11-13]. Analyzing the ratio between the number of short stay observations and E.R. admittances, we realize that in more than half of the cases, this ratio was less than $10 \%$, a number probably well below a reasonable level [8-11]. On the other hand, if we consider hospital admission rates after observation, data are in line with expectations: less than $20 \%$, in $61 \%$ of cases. Unfortunately, in $25 \%$ of the units, the admission rate was up to $21-40 \%$, and in $10 \%$ it even exceeded $40 \%$. As reported in one of the most extensive studies [10], the expected admission rate is about $20 \%$. We believe that percentages higher than the expected level indicate a need for a stricter adherence to the S.S.O. admission criteria. In other words, this healthcare model should be more rigorously regulated through the implementation of protocols planned to better define and clarify appropriate use and correct diagnostic and therapeutic criteria for each disease. We think that, when properly used, the S.S.O. model is an efficient tool to reduce inappropriate E.R. discharges and to increase patient safety and comfort. Furthermore, if correctly formalized, S.S.O. could lead to a rationalization of the National Health System's resources [14-16]. In fact, it could potentially reduce inappropriate hospital admissions, considering that many pediatric admissions last for less than $48 \mathrm{~h}$. These admissions increase the saturation of pediatric wards, take away resources more appropriately used elsewhere and sometimes force patients to stay in unsuitable environments or require a demanding and risky transfer to another hospital.

\section{Conclusions}

Our data highlight the heterogeneity of the Italian situation. Even though the moral wealth of our Country comes from a balanced combination of different cultures and traditions, when it comes to healthcare, we believe in the need for a wider homogeneity and uniformity. This could be accomplished by better regulating pediatric activities inside and outside of the hospital. This is not meant to trivialize physicians' functions and responsibilities with the strict adoption of protocols and procedures, but signifies the necessity to provide the medical staff with the appropriate tools to perform his work in a more correct and safer way.

Competing interests

The authors declare that they have no competing interests. 


\section{Authors' contributions}

RL has made substantial contributions to plan and design the study and has been involved in drafting and revising the manuscript. RP has made substantial contributions to acquisition and analysis of data. DM has made contributions to interpretation of data. ADCM has been involved in drafting and revising the manuscript. All authors read and approved the final manuscript.

\section{Acknowledgement}

The authors express their thanks and appreciation to Chiara and Ludovico Longhi for their contribution in translating of the manuscript.

\section{Author details}

'Unità Operativa di Pediatria, Ospedale Sant'Anna, San Fermo della Battaglia, Como, Italy. ${ }^{2}$ Unità Operativa di Pediatria, Ospedale di Polistena, Reggio Calabria, Italy.

Received: 12 June 2015 Accepted: 1 October 2015

Published online: 15 October 2015

\section{References}

1. Ministero della Salute Commissione Consultiva: Piano per i miglioramento del Sistema di Emergenza/Urgenza. Linee Guida per la riorganizzazione dei servizi di emergenza ed urgenza pediatrica. Accessed online http://www.salute.gov.it/imgs/C_17pubblicazioni_856 ulterioriallegati_ulterioreallegato_1_alleg.pdf (2005)

2. Consensus Meeting L'Osservazione Temporanea Breve in Pronto Soccorso Pediatrico: Linee Guida per la gestione dell'Osservazione Breve in Pediatria: 14-15 October 2005; Trieste. Accessed online http://www.sime2up.com/doc/ 1748718914_DocumentofinaleConsensusOT.pdf (2005).

3. Longhi R. Indagine della Società Italiana di Pediatria sullo stato della rete pediatrica ospedaliera in Italia. Atti $65^{\circ}$ congresso Nazionale S.I.P., Padova 2009. Minerva Pediatr. 2009;61:6-8.

4. Materia E, Fortino A, Lispi L. La valutazione dell'appropriatezza dei ricoveri ospedalieri in Italia. Accessed online http://www.salute.gov.it/imgs/C_17_ pubblicazioni_1001_allegato.pdf (2002).

5. Perletti L, Parizzi F, Gargantini G, Lispi L, Alfò M. La razionalizzazione del ricovero ospedaliero in età pediarica. Ospedale e Territorio. Accessed online http://www.salute.gov.it/imgs/C_17_pubblicazioni_999_allegato.pdf (2000).

6. Dougherty G. When should a child be in the hospital? Pediatrics. 1998;101:19-24.

7. Scanlon MC, Harris JM, Levy F, Sedman A. Evaluation of the agency for healthcare research and pediatric quality indicators. Pediatrics. 2008;121:1723-31.

8. Zebrack M, Kadish H, Nelson D. The pediatric hybrid observation unit: an analysis of 6477 consecutive patient encounters. Pediatrics. 2005;115:535-42.

9. Mace SE, Graff L, Mikhail M, Ross M. A National survey of observation units in the United States. Am J Emerg Med. 2003;21:529-33.

10. Gregory P. Sanford M. Committee on hospital care and committee on pediatric emergency medicine. Pediatrics. 2012;130:172-9.

11. DeCoster C, Peterson S, Karian P. Manitobe centre for health policy and evaluation: report summary alternatives to acute care. Manitoba: University of Manitoba-Manitoba Centre for Health Policy and evaluation; 1996.

12. Greenberg RA, Dudley NC, Rittichier KK. A reduction in hospitalization, lenght of stay, and hospital charges for croup with the institution of a pediatric observation unit. Am J Emerg Med. 2006;24:818-21.

13. Miescier MJ, Nelson DS, Firth SD. Children with asthma admitted to a pediatric observation unit. Pediatr Emerg Care. 2005;21:645-9.

14. Boyle AA, Robinson SM, Whitwell D. Integrated hospital emergency care impoves efficiency. Emerg Med J. 2008:25:78-82.

15. Bellet PS, Whitaker RC. Evaluation of a pediatric hospitalist service: impact on lenght of stay and hospital charges. Pediatrics. 2000;105:478-84

16. Hostetler B, Leikin JB, Timmons JA. Patterns of use of an emergency department-based observation unit. Am J Ther. 2002:9:499-502.

\section{Submit your next manuscript to BioMed Central and take full advantage of:}

- Convenient online submission

- Thorough peer review

- No space constraints or color figure charges

- Immediate publication on acceptance

- Inclusion in PubMed, CAS, Scopus and Google Scholar

- Research which is freely available for redistribution

Submit your manuscript at www.biomedcentral.com/submit 